\title{
Pengaruh Segmentasi Terhadap Hasil Rotasi Citra Menggunakan Metode Minimum Area Rectangle
}

\author{
Gusti Ngurah Sanditya Riantama, I Nyoman Piarsa, Gusti Made Arya Sasmita \\ Program Studi Teknologi Informasi, Fakultas Teknik, Universitas Udayana \\ Bukit Jimbaran, Bali, Indonesia, telp. (0361) 701806 \\ e-mail: sandityariantama@gmail.com, manpits@unud.ac.id, aryasasmita88@gmail.com
}

\begin{abstract}
Abstrak
Pengolahan citra digital memiliki beberapa tujuan, salah satunya untuk mengambil ciri dari citra sehingga dapat dikenali yang biasa disebut dengan ekstraksi ciri. Tahap pertama dalam ekstraksi ciri adalah akuisisi citra. Pengambilan gambar sebaiknya dilakukan pada keadaan posisi sama, jika tidak objek pada citra memiliki orientasi yang berbeda-beda sehingga lebih sulit dikenali. Rotasi citra diperlukan untuk mengembalikan citra pada orientasi yang seharusnya, yang pada penelitian ini menggunakan Metode Minimum Area Rectangle. Citra terlebih dahulu disegmentasi untuk memisahkan antara objek dengan background, selanjutnya objek dirotasi sebesar sudut yang didapatkan. Hasil segmentasi memiliki pengaruh yang besar terhadap hasil sudut rotasi yang didapatkan menggunakan Metode Minimum Area Rectangle. Semakin sedikit noise atau sisa background hasil segmentasi, semakin akurat sudut citra yang didapatkan. Perbedaan sudut terbesar yang didapatkan mencapai $29^{\circ}$.
\end{abstract}

Kata kunci: Rotasi, Orientasi Citra, Segmentasi, Minimum Area Rectangle

\begin{abstract}
Digital image processing has several objectives, one of which is to collect certain characteristics of the image commonly referred to as feature extraction. The first step in feature extraction is image acquisition. Image capture should be done in a state of stationary objects, if not the objects in the image have different orientations so that it is more difficult to recognize. Image rotation is needed to restore the image to its intended orientation. The image is first segmented to separate objects from the background, then the object is rotated at the angle obtained. The results of segmentation have a large influence on the results of the rotation angle obtained using the Minimum Area Rectangle method. The less noise or the remainder of the segmentation background, the more accurate the image angle is obtained. The biggest angle of difference can reach $29^{\circ}$.
\end{abstract}

Keywords: Image Rotation, Image Orientation, Segmentation, Minimum Area Rectangle

\section{Pendahuluan}

Ekstraksi fitur (feature extraction) adalah suatu metode yang digunakan untuk mengambil ciri objek pada suatu citra dengan tujuan mengenali objek tersebut [1]. Salah satu tahapan dalam ekstraksi fitur adalah akuisisi yaitu sebuah proses mendapatkan data citra dari analog ke bentuk digital [2]. Tahapan akuisisi biasanya menggunakan kamera sebagai alat untuk mendapatkan citra objek penelitian. Setiap kamera dapat menghasilkan berbagai gambar dengan orientasi yang berbeda-beda tergantung pada posisi pengambilan gambar. Faktor orientasi atau perputaran gambar menjadi salah satu permasalahan yang sering ditemukan dalam ekstraksi fitur pengenalan wajah [3]. Rotasi sangat diperlukan untuk mengembalikan orientasi citra pada posisi yang seharusnya.

Penelitian sejenis dengan topik koreksi sudut citra salah satunya dilakukan menggunakan Metode Projective Transformation [4]. Penelitian lainnya menggunakan fitur Haar-Like dan Adaboost untuk mendapatkan orientasi citra berdasarkan keberadaan tubuh manusia [5] dan metode yang sama dengan menggunakan keberadaan wajah [6]. Metode Minimum Area Rectangle digunakan dalam penelitian lainnya yaitu untuk koreksi sudut orientasi telapak tangan dengan jari tengah sebagai dasar penentuan orientasi [7]. 
Perbaikan orientasi citra juga dilakukan pada penelitian ini menggunakan Metode Minimum Area Rectangle pada perangkat Android dengan Open Computer Vision (OpenCV) sebagai library dalam proses pengolahan citra computer vision [8]. Pertama citra disegmentasi untuk memisahkan antara objek (foreground) dengan background yang ada pada citra, selanjutnya sudut rotasi objek dihitung menggunakan Minimum Area Rectangle dan dirotasi untuk mendapatkan posisi yang seharusnya. Penelitian ini bertujuan untuk melihat pengaruh hasil segmentasi terhadap nilai sudut yang didapatkan menggunakan Metode Minimum Area Rectangle.

\section{Metodologi Penelitian}

Penelitian tentang perbaikan orientasi citra menggunakan Metode Minimum Area Rectangle dilakukan melalui dua tahapan. Tahap pertama citra disegmentasi dan selanjutnya dirotasi berdasarkan sudut yang didapatkan. Citra yang digunakan didaptkan melalui pengambilan secara langsung menggunakan smartphone, maupun citra yang sudah ada pada galeri pengguna.

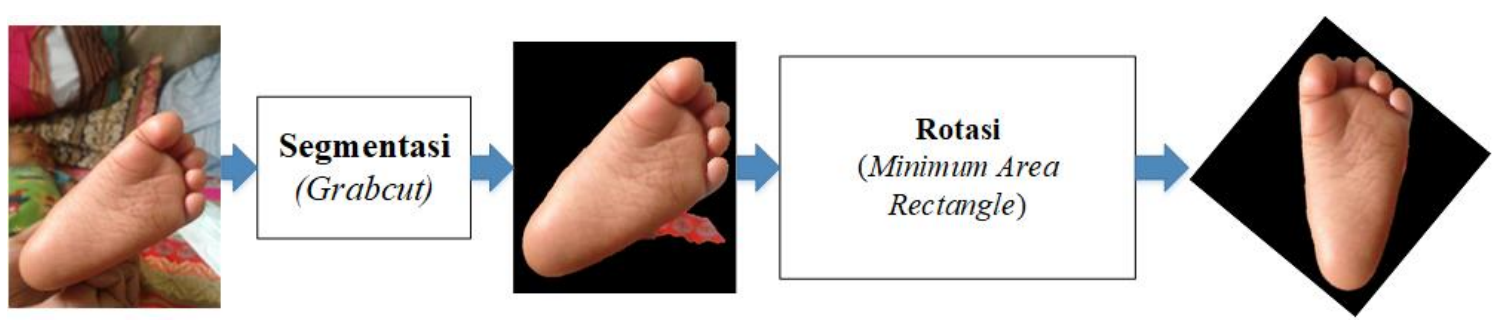

Gambar 1. Gambaran Umum Sistem

Gambar 1 merupakan gambaran umum penelitian normalisasi orientasi citra menggunakan Metode Minimum Area Rectangle. Citra awal yang digunakan diubah menjadi berukuran 200x200 piksel. Citra foreground yang digunakan dalam proses rotasi didapatkan dari hasil segmentasi citra dengan menggunakan Metode Grabcut. Tahap terakhir adalah proses mendapatkan nilai sudut dari citra, dan dirotasi untuk mendapatkan orientasi yang seharusnya dengan menggunakan Minimum Area Rectangle.

\section{Kajian Pustaka}

Kajian pustaka berisi tentang teori-teori penunjang yang digunakan sebagai dasar dalam melakukan penelitian. Teori-teori yang digunakan bersumber dari jurnal ilmiah penelitian sebelumnya. Segmentasi Grabcut dan Minimum Area Rectangle adalah teori penunjang yang dibahas dalam kajian pustaka

\subsection{Segmentasi Grabcut}

Segmentasi adalah sebuah teknik yang memisahkan citra menjadi beberapa daerah berdasarkan karakteristik tertentu [9]. Salah satu contoh metode segmentasi adalah Grabcut yang merupakan metode segmentasi citra yang dikembangkan dari Metode Graph Cut oleh Carsten Rother, Vladimir Kolgomorov, dan Andrew Blake dimana citra dibagi menjadi dua yaitu foreground dan background. Pengguna menggambar rectangle pada citra. Seluruh piksel yang ada diluar rectangle dikelompokan sebagai background, sedangkan piksel yang berada di dalam rectangle dikelompokan sebagai probably foreground. Gaussian Mixture Models (GMM) membuat kelas foreground dan kelas background dimana kelas background adalah piksel yang berada di luar rectangle dan piksel yang berada di dalam rectangle namun memiliki kemiripan warna dengan piksel yang berada di luar rectangle. Sisa piksel yang ada dikelompokan ke dalam foreground. Tiga kelebihan Grabcut dengan Graph Cut yaitu Metode Grabcut lebih optimal, menyederhanakan interaksi dengan pengguna untuk mendapatkan kualiatas hasil yang diinginkan, pengembangan batas objek foreground yang lebih kuat. Gambaran umum algoritma dari Metode Grabcut adalah sebagai berikut [10]. 
1. Pengguna membuat trimap awal dengan memilih rectangle. Piksel di dalam rectangle ditandai sebagai tidak diketahui dan piksel di luar rectangle ditandai sebagai background.

2. Semua piksel yang tidak diketahui ditempatkan pada kelas foreground dan semua piksel yang ditandai sebagai background ditempatkan pada kelas background.

3. Gaussian Mixture Model (GMM) dibuat untuk kelas foreground dan background awal menggunakan algoritma klustering Orchard-Bouman.

4. Setiap piksel dalam kelas foreground ditetapkan ke komponen Gaussian yang paling mungkin dalam GMM foreground, demikian pula setiap piksel di kelas background ditetapkan ke komponen Gaussian yang paling mungkin dalam GMM background.

5. GMM baru dibentuk dari set piksel yang dibuat pada set GMM sebelumnya.

6. Graph Cut dijalankan untuk menemukan bagian klasifikasi foreground dan background yang baru.

7. Langkah 4-6 diulangi sampai klasifikasi piksel tidak mengalami perubahan.

\subsection{Minimum Area Rectangle}

Minimum Area Rectangle adalah kotak (rectangle) terkecil yang mengelilingi poligon dari semua rectangle yang dapat dibentuk. Rectangle terbentuk melalui titik-titik terluar yang ada pada poligon. Tiap titik dapat membentuk lebih dari satu rectangle dengan ukuran yang berbeda-beda sesuai dengan titik pasangan rectangle lainnya.

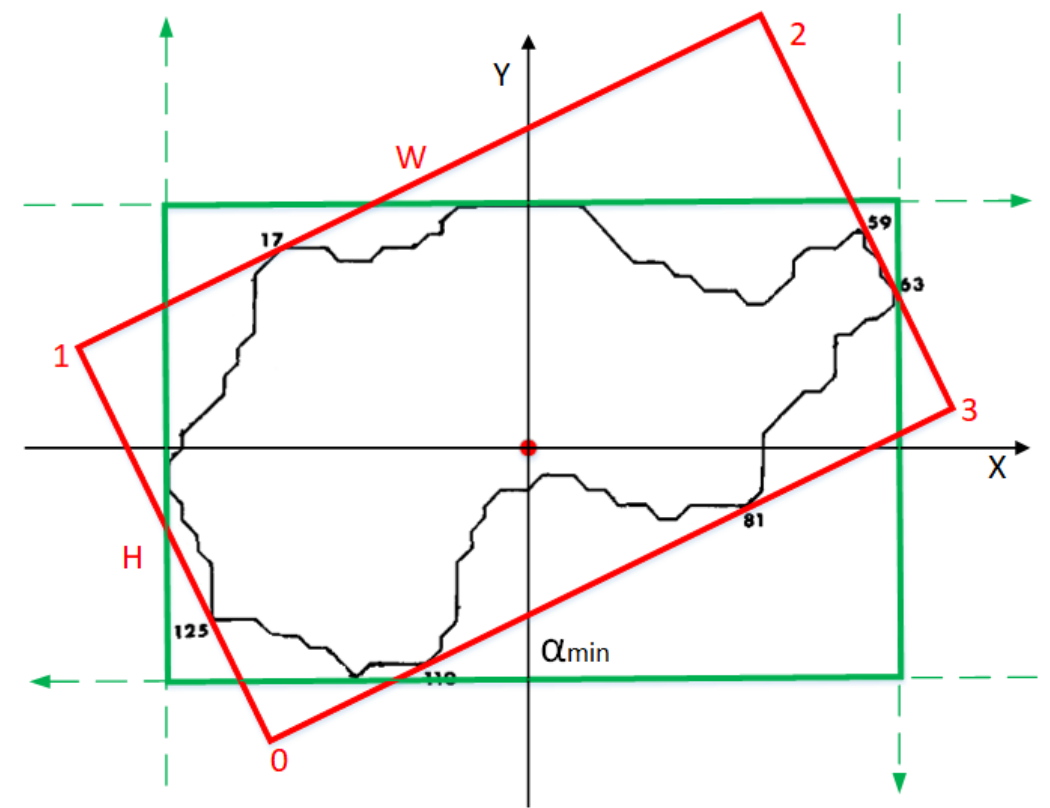

Gambar 2. Minimum Area Rectangle

Gambar 2 adalah ilustrasi dari Minimum Area Rectangle yang dapat dibentuk dari sebuah poligon. Minimum Area Rectangle pada citra didapatkan melalui dua proses yaitu pertama mencari Convex Hull, selanjutnya menentukan rectangle dari Convex Hull untuk mendapatkan daerah rectangle terkecil [11]. Minimum Area Rectangle pada OpenCV memiliki beberapa ketentuan sebagai berikut.

1. Titik paling bawah Minimum Area Rectangle (rectangle berwarna merah) merupakan titik 0 , dan titik 1, 2, dan 3 mengikuti searah dengan jarum jam.

2. Tinggi (height) adalah jarak antara titik 0 dengan titik 1 dan titik 2 dengan titik 3 , sedangkan lebar (weidth) adalah jarak antara titik 1 dengan titik 2 dan titik 3 dengan titik 0.

3. Rentang sudut yang didapatkan dari minAreaRect adalah -0 sampai dengan -90 .

4. $\quad$ Sudut dihitung dari garis horizontal ke daerah minimum area rectangle 0 dan 3.

5. Sudut bernilai negatif diputar searah dengan jarum jam, sedangkan sudut bernilai positif diputar berlawanan dengan jarum jam. 


\section{Hasil dan Pembahasan}

Bagian Hasil dan Pembahasan memuat pembahasan dari penelitian yang disajikan dalam bentuk deskripsi, gambar dan tabel. Hasil penelitian yang dibahas yaitu hasil segmentasi, dan pengaruhnya terhadap nilai sudut yang didapatkan menggunakan Metode Minimum Area Rectangle. Citra yang digunakan dalam penelitian ini adalah citra telapak kaki bayi yang diambil langsung melalui kamera smartphone.

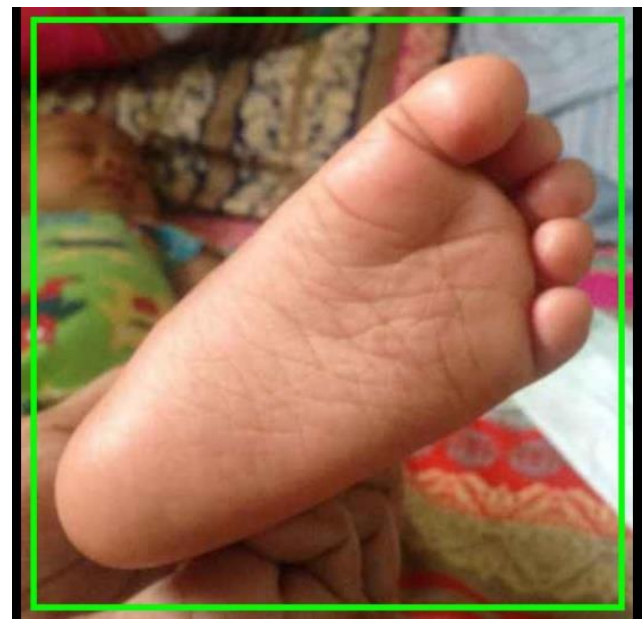

Gambar 3. Citra Telapak Kaki Bayi

Gambar 3 merupakan citra telapak kaki bayi yang digunakan. Citra telapak kaki bayi diambil secara acak dengan orientasi yang berbeda-beda. Pengambilan gambar diposisikan agar tidak ada bagian dari telapak kaki bayi yang terpotong atau tertutup.

\subsection{Hasil Segmentasi}

Segmentasi menggunakan Metode Grabcut membutuhkan rectangle untuk membagi gambar menjadi dua bagian yaitu background dan foreground. Ukuran rectangle berpengaruh dalam menentukan berapa besar daerah segmentasi. Seluruh pengujian segmentasi citra dilakukan menggunakan Grabcut dengan luas rectangle 180x180 piksel.

Tabel 1. Hasil Segmentasi

\begin{tabular}{|c|c|c|}
\hline Sebelum & Sesudah & $\begin{array}{c}\text { Waktu } \\
\text { Rata-Rata (s) }\end{array}$ \\
\hline & & \\
\hline
\end{tabular}




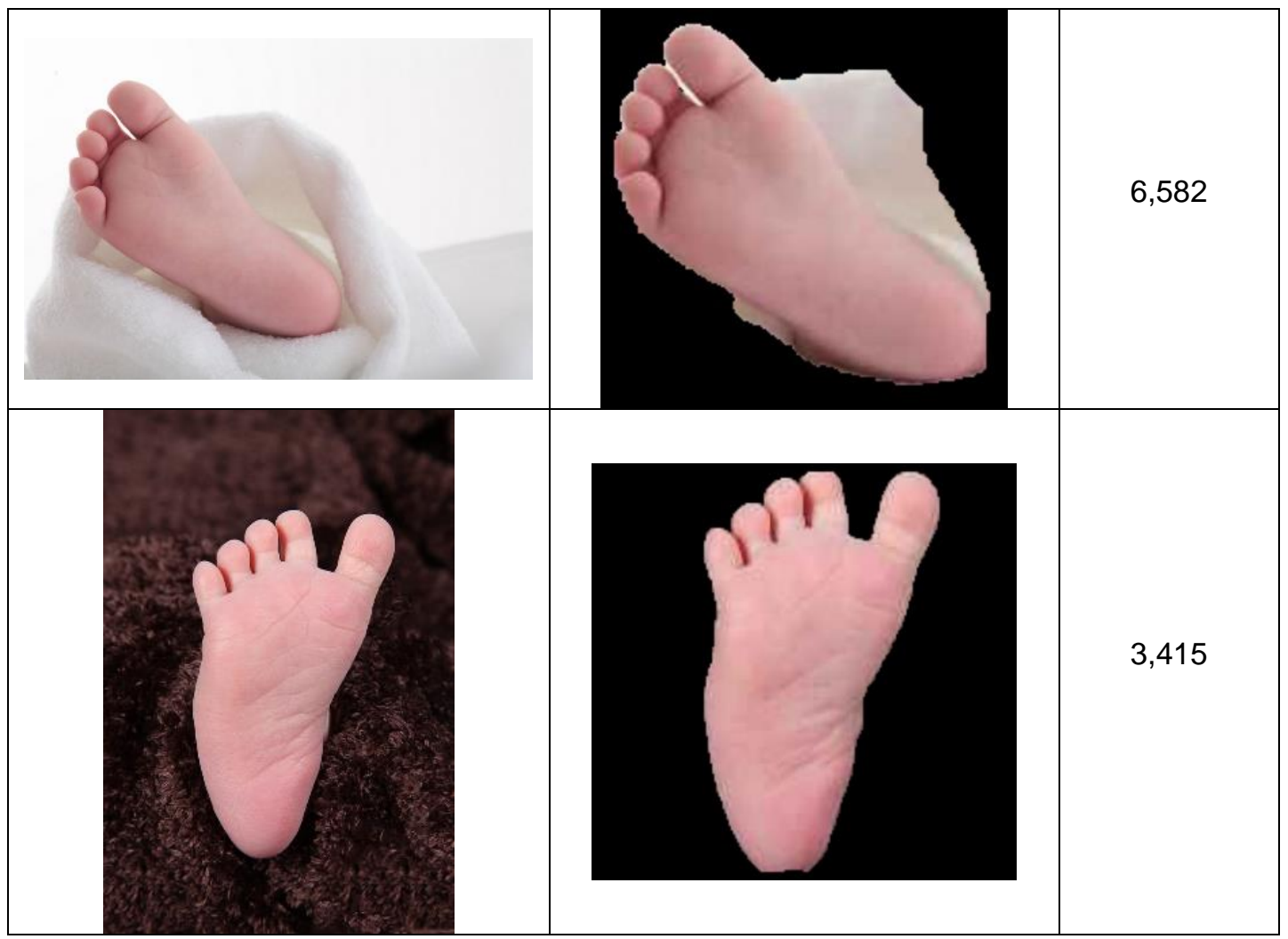

Tabel 1 merupakan hasil segmentasi menggunakan Metode Grabcut. Uji coba menggunakan 40 buah citra dan dilakukan pengujian sebanyak 3 kali iterasi untuk mendapatkan waktu rata-rata proses segmentasi citra. Citra hasil segmentasi tidak selalu bersih dari noise atau bagian dari background karena piksel warna berada di dalam daerah rectangle dianggap sebagi bagian foreground.

\subsection{Hasil Rotasi Menggunakan Metode Minimum Area Rectangle}

Rectangle yang digunakan dalam Metode Minimum Area Rectangle adalah rectangle terkecil yang dapat dibentuk dari kontur pada citra. Sudut didapatkan melalui perpotongan antara rectangle dengan garis bantu vertikal yang melewatinya.

Tabel 2. Pengaruh Kontur Hasil Segmentasi pada Minimum Area Rectangle

\begin{tabular}{|c|c|c|c|c|}
\hline No. & Kontur A & Kontur B & $\begin{array}{c}\text { Sudut } \\
\text { A }\end{array}$ & $\begin{array}{c}\text { Sudut } \\
\text { B }\end{array}$ \\
\hline 1 & & & \\
\hline
\end{tabular}




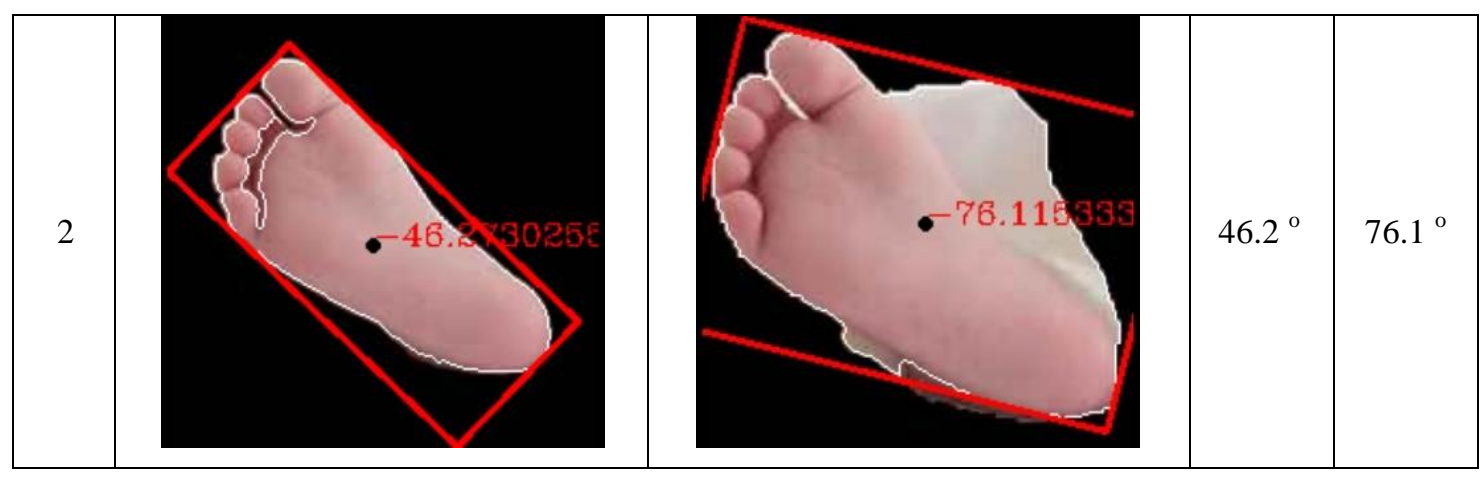

Tabel 2 merupakan hasil sudut yang didapatkan menggunakan Metode Minimum Area Rectangle. Kontur A merupakan kontur foreground dari citra yang bersih tanpa ada bagian background, sedangkan kontur B adalah kontur hasil segmentasi yang masih meninggalkan bagian background pada citra. Sudut yang didapatkan kontur A pada gambar pertama mendapatkan hasil $56.9^{\circ}$, sedangkan sudut pada kontur B mendapatkan hasil $61.6^{\circ}$. Gambar kedua, sudut yang didapatkan menggunakan kontur $A$ sebesar $46.2^{\circ}$, sedangkan menggunakan kontur B sudut yang didapatkan sebesar $76.1^{\circ}$. Sudut yang didapatkan menggunakan Metode Minimum Area Rectangle dipengaruhi oleh kontur dari citra yang digunakan.

Tabel 3. Hasil Rotasi Berlawan Arah Jarum Jam

\begin{tabular}{|c|c|c|c|}
\hline Sebelum & Sesudah & Sudut Awal (日) & $\begin{array}{c}\text { Waktu } \\
\text { Rata-Rata (s) }\end{array}$ \\
\hline & & & \\
\hline
\end{tabular}

Tabel 3 merupakan hasil rotasi citra menggunakan Metode Minimum Area Rectangle pada kuadran 1 . Sudut yang didapatkan bernilai positif yang menunjukan putaran rotasi citra berlawan arah dengan jarum jam. Waktu rata-rata yang dibutuhkan untuk rotasi citra adalah 0.15 detik. 
Tabel 4. Hasil Rotasi Searah Jarum Jam

\begin{tabular}{|c|c|c|c|}
\hline Sebelum & Sesudah & Sudut Awal (日) & $\begin{array}{c}\text { Waktu } \\
\text { Rata-Rata (s) }\end{array}$ \\
\hline & & & \\
\hline
\end{tabular}

Tabel 4 merupakan hasil rotasi citra menggunakan Metode Minimum Area Rectangle pada kuadran 2. Sudut yang didapatkan bernilai negatif yang menunjukkan putaran rotasi citra searah dengan jarum jam. Waktu rata-rata yang dibutuhkan untuk rotasi citra adalah 0.14 detik.

\section{Kesimpulan}

Sudut rotasi citra menggunakan Metode Minimum Area Rectangle dipengaruhi oleh hasil kontur dari segmentasi citra. Rectangle mengelilingi objek dan noise menyebabkan nilai sudut yang didapatkan bukan nilai sudut objek yang sebenarnya, melainkan berasal dari gabungan antara objek dan noise. Semakin sedikit noise atau sisa background hasil segmentasi, maka semakin akurat sudut citra yang didapatkan. Perbedaan sudut citra yang didaptkan mencapai $29.9^{\circ}$.

\section{Daftar Pustaka}

[1] I W. A. Suryawibawa, I K. G. D. Putra, N. K. A. Wirdiani, "Herbs Recognition Based on Android using OpenCV", International Journal of Image, Graphics and Signal Processing (IJIGSP), Vol. 7, No.2, pp. 1-7, 2015.

[2] N. K. A. Wirdiani, S. Sukma, O. Sudana, K. S. Wibawa, "Balinese Papyrus Manuscript Image Segmentation Using DBSCAN Clustering Method", Journal of Theoretical and Applied Information Technology, Vol. 96, No. 7, pp. 5995-6005, 2018.

[3] I K. S. Widiakumara, I K. G. D. Putra, K. S. Wibawa, "Aplikasi Identifikasi Wajah Berbasis Android", Lontar Komputer, Vol. 8, No. 3, pp. 200-207, 2017.

[4] N. B. A. Mustafa, F. Bakri, S. K. Ahmed, "Identification of Image Angle Using Projective Transformation: Application to Banana Images", IEEE Region 10 Symposium, Kuala Lumpur, 2014: 408 - 413

[5] A. H. Abror, H. Tjandrasa, "Perbaikan Orientasi Citra Berdasarkan Keberadaan Manusia Menggunakan Fitur Gradien dan Haar-Like", JUTI: Jurnal IImiah Teknologi Informasi, Vol. 13, No. 2, pp. 107-115, 2015.

[6] A. H. Abror, H. Tjandrasa, "Orientasi Citra Secara Otomatis Berdasarkan Keberadaan Wajah Menggunakan Fitur Haar-Like", Melek IT Information Technology Journal, Vol. 1, No. 1, pp. 2-6, 2015. 
[7] Z. M. Noh, A. R. Ramli, M. Hanafi, M. I. Saripan, A. Khmag, "Method for Correcting Palm Vein Pattern Image Rotation by Middle Finger Orientation Checking", Journal of Computers, Vol. 12, No. 6, pp. 571-578, 2016.

[8] I P. P. Andika, I P. A. Bayupati, N. K. A. Wirdiani, "Rancang Bangun Aplikasi Pendeteksi Tipe dan Nilai Resistor Berbasis Android", Lontar Komputer, Vol. 6, No. 1, pp. 61-72, 2015.

[9] G. B. Adhi, I. D. Wahyono, "Segmentasi Gambar Warna Menggunakan Sauvola Modifikasi Fuzzy C-Means (SMFCM)", Lontar Komputer, Vol. 5, No. 2, pp. 416-423, 2014.

[10] A. Deshpande, Dr. P. Dahikar, Dr. P. Agrawal, "An Experiment with GrabCut Interactive Segmentation Technique on Specific Images", International Journal of Scientific \& Engineering Research, Vol 8, Issue 1, pp. 345-349, 2017.

[11] H. Freeman, R. Shapira, "Determining the Minimum-Area Encasing Rectangle for an Arbitrary Closed Curve", Communications of the ACM, Volume 18, Issue 7, pp 409-413, 1975. 